\title{
SPILLOVERS AND GOVERNANCE: AN ANALYSIS OF KNOWLEDGE AND REPUTATIONAL SPILLOVERS IN INFORMATION TECHNOLOGY
}

\author{
KYLE J. MAYER \\ University of Southern California
}

\begin{abstract}
Investigating spillovers (potential costs and benefits to a firm that extend beyond an individual transaction), I integrate transaction cost theory and the knowledge-based view of the firm in an effort to better understand the efficient governance of knowledge. Contracts with detailed task descriptions were associated with transactions with the potential to generate new and reusable knowledge. The risk of a firm's technology spilling over to others and the risk of reputation-impairing spillovers were associated with suppliers using their own employees rather than subcontractors. Thus, results suggest that the creation and protection of knowledge are key factors in understanding governance decisions.
\end{abstract}

As more complex and core activities are being outsourced, deciding how to govern relationships with customers and suppliers has become more strategically important. Firm-level capabilities (Argyres, 1996; Demsetz, 1991; Kogut \& Zander, 1992) and contracting hazards arising from a transaction (Williamson, 1985) influence how that transaction will be governed, but so can factors related to knowledge and past governance choices (Argyres \& Liebeskind, 1999). The purpose of this study was to integrate transaction cost theory and the knowledge-based view of the firm to explore how firms govern transactions that involve spillovers, which I define as benefits or costs that accrue to one or both of the parties to a transaction that go beyond the scope of the transaction. For example, if a supplier performs poorly in an exchange, it may not only lose the revenue it was supposed to receive from that transaction, but also the revenue from future transactions with that customer-or from transactions with other customers, if poor performance damages the supplier's reputation.

Although this example illustrates a negative reputational spillover, other spillovers can provide future benefits, including the creation of knowledge that can be reused to lower the cost of completing future transactions. In this study I also examined positive reputational spillovers (performing well on critical projects) and negative knowledge spillovers (such as the loss of technology). Both knowledge and reputation spillovers can have positive and negative

I would like to thank Tom Cummings, Julia Liebeskind, Anita McGahan, Nandini Rajagopalan, Don Bergh (editor), and three anonymous referees for their thoughtful comments. effects. I examined how firms manage the costs and benefits that may accrue to future transactions as a result of actions in current transactions, as these actions may affect firm profitability.

I chose to examine spillovers because they provide an excellent opportunity to integrate transaction cost theory, which is relevant as spillovers influence governance, and the knowledge-based view of the firm-relevant in that governance choices can affect a firm's stock of knowledge. Transaction cost theory has focused on governance as a response to contractual hazards arising from transactions. Little attention has been paid to how factors that extend beyond a focal transaction affect governance decisions (see Argyres and Liebeskind [1999] for an exception). The influence of spillovers on governance has received little attention despite the fact that spillovers can have a significant effect on a firm's competitive position by adding to or devaluing the firm's resources (e.g., knowledge and reputation). Transaction cost research has also paid relatively little attention to how firms might govern transactions with potential spillovers resulting from the ability to reuse newly created knowledge.

The knowledge-based view (Grant, 1996; Kogut \& Zander, 1992) examines how firms can increase their stock of knowledge, which is believed to be the key driver of competitive advantage and firm scope. Toward this end, scholars studying the knowledge-based view of the firm have examined how knowledge considerations influence choice of alliance type (Gulati \& Singh, 1998) and alliance performance (e.g., Madhok \& Tallman, 1998; Zollo, Reuer, \& Singh, 2002). I build on this work by examining how a transaction's potential to create 
reusable knowledge or to protect existing knowledge influences vertical integration and the contract used to govern the exchange.

This study's dependent variables represent the significant governance choices most likely to be affected by knowledge and reputation concernssupplier integration decision and the level of detail in customer-supplier contracts. I examined contracts signed between a customer and a supplier to determine the level of detail they employed in response to the potential for reputation and knowledge spillovers. The level of detail is very important in the management of the customer-supplier relationship. Insufficient detail can lead to inconsistent expectations, but excessive detail can lead to delays and may be interpreted as a signal of distrust. Then I examined how potential spillovers influence a supplier's decision about whether to complete the given project with employees or a subcontractor.

This article contributes to the literature on strategic management in three ways. First, it incorporates consideration of spillovers into governance decisions and evaluates the effects of knowledge on interfirm governance. Knowledge considerations influence the structure of the contracts suppliers sign with customers, not just the boundaries of firms. Second, the study shows that the potential for knowledge reuse and reputation-impairing spillovers result in the use of different governance mechanisms. Third, this study explores integration of transaction cost theory and the knowledge-based view in an attempt to help advance understanding of the role knowledge creation and protection play in two important governance choices. Transaction cost analyses of governance may benefit from a more careful consideration of the role of knowledge, while the knowledge-based view may benefit from a closer look at the key role of different governance mechanisms in knowledge creation and protection.

I examined the effects of spillovers in 303 contracts from a large supplier (hereafter referred to as "Compustar") in the information technology (IT) services industry. The contracts, along with interviews with several of the firm's managers and engineers, enabled me to identify both knowledge and reputational spillovers, and a variety of other exchange attributes.

\section{THEORY AND HYPOTHESES}

\section{Reputation and Knowledge Spillovers}

Transaction cost theory (Williamson, 1985, 1996) has primarily focused on how attributes of a trans- action, mainly contractual hazards arising from specific investments, affect how it should be governed. Empirical transaction cost research (see Shelanski and Klein [1995] for an overview) has examined both vertical integration and clauses of customer-supplier contracts as responses to a variety of contractual hazards. There is debate about the extent to which transaction cost theory acknowledges the power of the social and institutional context (Granovetter, 1985; Williamson, 1996), but few have considered how the governance of a transaction may be influenced by factors outside the transaction itself. Argyres and Liebeskind (1999) discussed this issue when examining governance inseparability, which involves constraints arising from prior governance choices.

A related issue that has received little attention is how spillovers (a transaction's potential effects on future transactions) influence governance. Firms first see the potential for spillovers in a project and then take this into account when choosing how to govern the transaction. The governance choice affects the firm's ability to realize (or avoid) the spillovers. The parties foresee the possibility of spillovers and respond by crafting appropriate governance.

Research on the effects of spillovers on governance has shown that firms integrate to avoid the costs of spillovers arising from damage to their reputations (Nickerson \& Silverman, 2003). When observed firms outsourced when there was potential for reputational spillovers, they extensively monitored suppliers (Mayer, Nickerson, \& Owan, 2004). Yet although reputation has been the subject of significant research, its influence on contract design has yet to be fully explored.

Firm reputation is a valuable asset with multiple dimensions (Fombrun \& Shanley, 1990) and can be a function of product quality, managerial competence, and other factors valued by external constituencies (Tsui, 1984). Research on reputation has examined governance but has focused on alternatives to contracts for ensuring performance (e.g., Hennart, 1991; Kogut, 1988). Reputation has also been characterized as a hostage firms can use to ensure that transaction partners will exert high effort (Klein \& Leffler, 1981), and as a source of differentiation (e.g., Erdem \& Swait, 1998; Rao \& Ruekert, 1994; Shapiro, 1985). Kreps (1990) posited that internal governance mechanisms are designed to create and protect a firm's reputation. If reputation can affect choices of alliance partners (e.g., Dollinger, Golden, \& Saxton, 1997; Houston, 2003; Kim, Lin, \& Slovin, 1997; Stuart, 1998), it may also influence alliance contracts. The ability of a transaction to affect a firm's reputation will be a key issue 
in governance because it can influence the firm's ability to win future business.

In addition to reputation, knowledge spillovers can also affect a firm's competitive position. Research on knowledge spillovers has focused almost exclusively on their existence and/or impact (Bresnahan, 1986; Mansfield, 1988, 1991). Compustar, the firm in this study, provides a good illustration of such knowledge spillovers. It developed a "help desk" system for routing calls that worked with a database program created by Oracle. The project resulted in code that could be reused for other firms that used Oracle database software, which is very common. Completing the first project allowed Compustar to do subsequent projects much more quickly.

The knowledge-based view and transaction cost theory approach the study of firms in different ways. The knowledge-based view (Grant, 1996; Itami, 1997; Kogut \& Zander, 1992) deals with integration in terms of information processing and a firm's knowledge base, while transaction cost theory (Williamson, 1985, 1996) focuses on governance. With the exception of a few papers on expropriation (Oxley, 1997; Pisano, 1990), research that draws upon transaction cost theory has paid little attention to knowledge. Proponents of the knowledge-based view, on the other hand, have yet to fully consider how governance tools such as contracts can affect a firm's knowledge base and ability to assimilate or protect knowledge.

\section{The Governance of Spillovers}

In many industries, especially service industries, production involves customized projects rather than repeated exchanges of identical goods or services. Each project is a separate transaction. Customized projects are important in many high-technology industries (e.g., software, information technology, semiconductors, and telecommunications) and in many settings not often considered high-technology contexts (e.g., construction, machine shops, film and television production).

The concerns of customers and suppliers engaged in such projects are likely to affect two key aspects of governance, particularly when the potential for spillovers is present: the detail used to describe a task in a contract ${ }^{1}$ and whether the supplier

${ }^{1}$ Although economists have examined completeness (e.g., Grossman \& Hart, 1986), I believe that examining specific aspects of a contract rather than its "completeness" offers a better view of spillovers. In addition, completeness is a subjective concept; Crocker and Reynolds should complete the project in-house or subcontract it. Contracts with more detailed task descriptions can help the parties align their expectations. Problems can arise from misunderstandings, opportunism, incompetence, or unforeseen exogenous factors. A more detailed description of a task decreases the risk of opportunism and misunderstandings. Crafting a more detailed contract can be costly, however, because it takes time and effort and may delay the start of the project. Thus, the involved parties must determine how much detail will maximize their chances of successfully completing the project. Contracts do not create spillovers, but they can be used to help firms manage projects to realize more knowledge benefits from them. The second governance choice, the supplier's decision about how to complete the project, involves choosing to use employees or a subcontractor. Both customer and supplier must agree on the level of contract detail, but the decision to subcontract rests primarily with the supplier. Subcontracting can be desirable owing to gaps in the supplier's internal skill base, a lack of available internal resources, and advantageous governance properties (Williamson, 1996).

\section{Knowledge-Based Spillovers}

The influence of spillovers has been examined in a variety of contexts (see Boerner, Macher, \& Teece [2001] for a review) that underscore the difficulty of maximizing their value (Jaffe, 1986). Little is known about how firms can govern buyer-supplier projects to increase the chances that benefits will accrue from potential knowledge spillovers. The knowledge-based view promotes integration to protect or create critical knowledge, but if knowledge is created in an interfirm transaction, integration is not possible, and the firms will need to seek other governance solutions, often in the contract governing the exchange.

The potential for positive knowledge spillovers, such as a supplier's potential reuse of knowledge from a project, creates two related contracting problems-uncertainty and opportunism. New knowledge is inherently uncertain, so there may be multiple ways to try to complete the buyer's task, and the two firms need to have a common understanding of what is to be done and how it will be done so as to maximize the chances of success. In addition, when knowledge reuse is an issue, an incentive

(1993) defined it in terms of price-more complete contracts have a fixed price, and less complete ones include more price contingencies. 
problem is created. The customer will seek a customized product that is optimized for its environment, while the supplier may opportunistically sacrifice optimality in the customer's context to create a more generic product to enhance reuse.

One response to these conflicting incentives and the need to align expectations is a contract with detailed task descriptions to ensure that the product will be acceptable to both parties. Such detail may spell out more customer-specific or reusable components of the project. For example, a customer may insist on a very detailed contract for a new help desk system that specifies exactly what the system must do. But this does not mean that the system will not be useful to other customers. The supplier may include details on the architecture of the system to facilitate its reuse with other customers.

Even if the buyer does not appreciate the reuse issue, the supplier still has an incentive to draft highly detailed task descriptions to maximize the amount of reusability while still giving the customer what it wants. If insufficient detail is used, then the customer may take advantage of the ambiguity and demand that the supplier create a highly customized solution that limits reuse.

Very detailed task descriptions ensure that the supplier cannot opportunistically deliver a generic solution that is not optimal for the customer's environment, while the customer cannot redefine project requirements in such a way as to eliminate the supplier's opportunity to reuse some of the knowledge. In informal interviews I conducted, software and IT executives indicated that they often discount bids for jobs that will create knowledge they can use in the future. If the customer changes the requirements during the project, then the anticipated future benefits, which were a part of the bid calculation, may be lost. This scenario also helps explain why expectations are documented in a contract. Parties think carefully before agreeing to add something to a contract. Thus, a contract with a highly detailed task description can protect both parties from problems arising from opportunism and help to align their expectations to maximize the probability of project success.

Hypothesis 1a. The more potentially reusable knowledge a project is likely to create, the more detailed the task descriptions in the customersupplier contract for the project.

The potential for knowledge spillovers can also influence whether to complete project tasks internally or subcontract them (Kogut \& Zander, 1992). Suppliers may use employees for projects with potential knowledge spillovers so that they, rather than the subcontractors, can capture reusable knowledge and/or prevent others from accessing their existing proprietary technology. Knowledge is critical to all firms, particularly those in high-technology industries, so the opportunity to reap the benefits of reusable knowledge and avoid expropriation of their existing technology are important for sustaining competitive advantage (Teece, 1986).

When knowledge spillovers involving reusability or expropriation of existing technology are present, suppliers will be reluctant to subcontract for fear of subcontractor opportunism. Although small numbers bargaining (Pisano, 1990) and knowledge intensity (Azoulay, 2003) have been shown to lead to a preference for integration, I examined a different issue-how the reusability of the knowledge created and exposure to a firm's existing proprietary knowledge affect a supplier's project-level sourcing decisions.

Both transaction cost theory and the knowledgebased view promote integration in the presence of knowledge spillovers. Transaction cost theory promotes the benefits of overcoming subcontractor opportunism in order to protect a firm's knowledge. The knowledge-based view promotes integration so that the firm can increase its stock of knowledge and further its competitive advantage by using the new knowledge as a catalyst for recombining and transforming existing knowledge. It may be more difficult for a supplier to assimilate knowledge created during a project if a subcontractor is used, because the subcontractor may hide key aspects of the new knowledge from the supplier and keep it for himself. Even if the supplier can assimilate the knowledge for possible future use, the subcontractor may have it as well and may share it with other firms, thus limiting the competitive advantage the knowledge can provide the supplier.

Firms want to maximize the benefits of reusable knowledge, yet they also want to protect their existing knowledge. Expropriation concerns (Oxley, 1997) impact governance because loss of valuable intellectual property may affect a firm's ability to win future business. Customers pose a minimal expropriation risk because they are not exposed to the supplier's proprietary technology, but subcontractors require detailed access to the technology involved in their portion of a project. Integration does not guarantee the technology will be protected, as employees may leave a firm and take their knowledge to another firm, but the risk of losing key technology to subcontractors is greater than the risk of losing such technology via employees for two reasons. First, subcontractors have an existing customer base that allows them to use a technology immediately, while employees would 
have to leave their firm and find customers. Second, firms monitor employees who leave with proprietary technology and often require noncompete or nondisclosure agreements. Thus, employees represent less risk to firms when dealing with key existing knowledge and maximize the chances of profitably utilizing newly created knowledge because of the reduced threat of opportunism.

Hypothesis $1 b$. When a project involves knowledge spillovers-either protection of a supplier's existing knowledge or the creation of new knowledge-it is more likely to be completed by the supplier's employees than by a subcontractor.

\section{Reputation Spillovers}

Reputation is a key strategic asset that firms strive to build and protect (e.g., Grant, 1991; Hall, 1992). It can provide competitive advantage by serving as a point of differentiation (Klein \& Leffler, 1981; Rao \& Ruekert, 1994), giving firms access to scarce resources (Pfeffer \& Salancik, 1978), and attracting better alliance partners (Ahuja, 2000; Houston, 2003). In many industries customers rely on a firm's reputation to form an expectation of its performance (e.g., Kogut, 1988; Macaulay, 1963).

It takes time for firms to develop a reputation for quality, reliability, and so forth, and maintaining that reputation can be difficult (Rindova \& Fombrun, 1999). Reputation, though slow to build, can be lost quickly. A solid reputation can be built by successfully completing projects on schedule. Transactions differ, however, in their potential to affect a supplier's reputation. Some transactions have limited visibility and contribute little to a firm's reputation, either positively or negatively. Other projects are much more critical to customers; mistakes can diminish a supplier's reputation, while its reputation can be enhanced by good performance.

Problems can arise between the customer and supplier in highly visible projects for two reasons. First, customers may act opportunistically by asking suppliers to do more than was initially agreed on because they know the projects are important and highly visible for the suppliers. Second, there may be an honest misunderstanding between customer and supplier as to what is expected from the supplier for project completion. A customer may misinterpret this misunderstanding as supplier opportunism. A contract that contains detailed task descriptions can alleviate both of these concerns. However, negotiating very detailed task descriptions is time-consuming and costly, so firms care- fully choose the level of detail required to effectively govern a given project. Highly visible projects that can affect supplier reputation create incentives to draft contracts with very detailed task descriptions to clarify what is required and avoid problems from incompatible expectations or opportunistic customer demands. When a project is highly visible and important to the customer, both parties will want to minimize the likelihood of problems arising from misunderstandings or opportunism, and thus both will be motivated to include highly detailed task descriptions in the contract.

Hypothesis 2a. The greater the potential for a project to influence a supplier's reputation, the more detailed the task descriptions in the customer-supplier contract.

Integration can provide additional controls against shirking or other opportunistic acts by workers assigned to a project. Brickley and Dark (1987) found that franchisees were more willing than company managers to lower quality when the reputation effects were borne by the franchise. Contracts that specify damages should subcontractors act opportunistically are typically not feasible; even if a third party could verify such behavior, agreeing upon the cost to a firm's reputation is costly, if not impossible (Hart \& Moore, 1990; Nickerson \& Silverman, 2003). This costliness makes it difficult for a supplier to force a subcontractor to provide compensation for any damage the subcontractor's incompetence or opportunism causes to the supplier's reputation. Moreover, initiating litigation can damage a supplier's reputation by making it appear overly litigious.

Transaction cost theory highlights several reasons why integration should be preferred when a project can significantly affect a firm's reputation. First, firms have more control over employees than over subcontractors; the former can be directed at management's discretion, but the latter are subject only to the terms of their contracts. Second, employees' fiduciary duty to act in their employer's interests (Masten, 1993) creates more risk for employees (than for contractors) if the employees act opportunistically. Third, firms can align the incentives of employees with the firms' through a variety of financial instruments, such as vesting options, performance bonuses, and profit sharing (Liebeskind, 1997). If firms suffer financially because of diminished reputation, then layoffs or bankruptcy may follow, which would threaten employees directly. Fourth, socialization of new employees and the building of loyalty between employees and an organization can further reduce the incentive for 
employees to undertake actions that would damage the firm's reputation (Chatman, 1991). Finally, suppliers are better able to verify the capabilities of employees than the capabilities of subcontractors, who may misrepresent their skill sets and perform poorly, damaging the supplier's reputation. ${ }^{2}$ Even if it is a subcontractor who makes a mistake, responsibility for the project rests with the supplier. If anyone involved in the project makes a mistake, then the supplier is accountable in the eyes of the customer and the industry. ${ }^{3}$ Thus, the risks of subcontractor opportunism exceed those of employee opportunism because of several features of the employment relationship, which favors the use of employees when a supplier's reputation is at stake.

Hypothesis $2 b$. The greater the potential for a project to influence a supplier's reputation, the less likely the supplier is to utilize a subcontractor for the project.

\section{EMPIRICAL ANALYSIS}

\section{Data and Context}

I tested the hypotheses with data from Compustar, a provider of a variety of information technology services and computer-related hardware. The IT industry was ideal for testing the hypotheses, as both knowledge and firm reputation are important sources of competitive advantage. This industry involves the storage, transfer, and management of information, typically using mainframes, servers, or related devices. It includes three tiers: customers (e.g., Fortune 500 firms), suppliers (e.g., IBM, Fujitsu, CSC), and subcontractors. The suppliers perform a variety of IT projects for their customers, including designing customized software systems, updating software or hardware systems, and assisting with network design. The technologies in this industry include IBM-compatible mainframes, OS/390 programming, databases (e.g., Oracle, Informix), and customized software support and development in a variety of languages. Capabilities in this industry are technology-specific rather than firm-specific, which means that subcontracting options are always available.

\footnotetext{
${ }^{2}$ Although regular subcontractors are less of a risk than new ones, firms have more information about employees than about any subcontractor, and more ability to direct the training of employees.

${ }^{3}$ If subcontractors are large firms with established brand names, then their incentives to perform may be stronger. However, in most industries, including IT, this is not the case.
}

Work is performed on a project basis. Customers identify an IT project and then secure resources to complete it. Each project is sourced separately. A customer may engage IBM for one project and CSC for another, and these suppliers must decide how to fulfill the project requirements. A supplier's sourcing decision is particularly important because the project team typically interacts directly with the customer in the course of work performed at the customer's site. In many cases, independent subcontractors are utilized to fulfill projects for customers. In the IT services industry, subcontractors are often smaller firms with specialized skills in relatively narrow areas. Some subcontractors work exclusively with large IT service suppliers, and others work with IT service suppliers on some projects and directly with end customers on others.

The construction industry has a tiered structure that is similar to the structure of IT services. In construction, a customer hires a general contractor who then engages subcontractors for significant portions of the project (Eccles, 1981). There are too many specialties, and demand is too volatile, for general contractors to keep all possible specialties in-house. In addition, market entry is easy, and customers have little information about the quality of subcontractors. Customers also lack expertise in managing subcontractors. These factors also play a key role in the structure of the IT services industry, including the prevalence of subcontracting.

Consider an IT project that a customer has decided to outsource. The primary reason for the customer to outsource, as with construction, is a lack of the capabilities required to complete the task. Customers usually engage larger suppliers, such as Compustar, rather than go directly to subcontractors, for two reasons. First, there is the issue of finding suitable subcontractors, as they tend to be small firms. Second, there is the problem of verifying subcontractors' capabilities and avoiding opportunistic subcontractors. A large IT supplier must be concerned with its reputation, but reputation is a weak tool for controlling small firms (even single-person "firms") that can declare bankruptcy and change their names if they are sued or receive too much negative attention. Many subcontractors are individuals who wish to have flexible work hours and assignments. IT suppliers such as Compustar afford customers the protection of contracting with a reliable firm that is liable for problems with projects.

Compustar, a producer of mainframes and related hardware since the 1970s, entered the platform-independent IT services business in the mid 1980s and, by 1997, its IT services division accounted for revenues of approximately $\$ 100$ mil- 
lion worldwide. This growth was accomplished through the development of an internal delivery force and the use of a variety of subcontractors. As is typical of large IT firms such as IBM and CSC, Compustar relies heavily on its reputation and knowledge base as sources of competitive advantage.

Compustar provided access to all IT service contracts in its corporate contracts library, which dated from 1986 to early 1998. In this study, I analyzed a sample of 405 of Compustar's IT contracts with North American customers. Missing data, mainly on project size, caused me to drop 102 observations, so the final sample consisted of 303 contracts that represented a random sample of Compustar's contracts. I selected the sample on the basis of the first letter of each customer's name to generate an unbiased sample. The projects in this sample consisted of all contracts between Compustar and 141 customers and accounted for approximately 25 percent of the entire population of Compustar IT service contracts. A review by Compustar personnel indicated that this sample was representative of the full population of contracts on characteristics that included customer industry, customer size, and number of contracts between Compustar and the firm.

In addition to reading the contracts, I interviewed several Compustar managers and engineers, and IT personnel from outside Compustar. The data were drawn primarily from the Compustar-customer contracts, subcontractor invoices, and other records in the contract files. Each contract contained a detailed description of the project, including the type of service required and the responsibilities of the parties, and was typically about five pages long. Compustar provided two engineers to help with coding variables that required subjective judgment and thus could not be directly coded from the contracts. Some projects were fixed-fee arrangements; others stipulated an hourly rate. Project duration ranged from a few days to over a year.

\section{Variables and Methodology}

Dependent variables. The study had two dependent variables. Description captured the amount of detail in the Compustar-customer contract that went into describing the task; it ranged from 1, "virtually no description of task (open-ended)" to 7 "great detail used to describe the task and roles and responsibilities of both parties." This variable was correlated at 0.9 with the number of sentences used to describe the task, which I counted to correct for differences in how various authors of contracts wrote task descriptions. The coders for the description variable were the Compustar engineers, who were experts on information technology.

The second dependent variable, subcontract, was a dummy variable coded 1 if a subcontractor was involved in a project and 0 if the project was completed using only in-house personnel. I coded "subcontract” from the records in each project file. Data limitations precluded the use of any finer-grained dependent variable capturing level of subcontractor involvement. However, the invoices indicated that subcontractors were rarely involved in only a peripheral manner. The potential for malfeasance is present whenever a subcontractor is responsible for any portion of a project. Compustar served as project manager for all projects.

Independent variables. Positive knowledge spillovers were captured by reuse, a variable resulting from two steps of analysis. First, the Compustar engineers coded projects for the extent to which they required innovation (1, "requires no innovation to complete," to 7, "cannot be completed without a technological breakthrough"). ${ }^{4}$ The engineers then went back and assessed whether the newly created knowledge was likely to be reusable, drawing upon their expertise and records in the contract file. Reuse was coded only from the contract and did not involve seeking to discover what happened during the project.

The need to protect Compustar's existing proprietary technology was expected to decrease the likelihood of subcontracting because allowing existing knowledge to leak to other firms is a negative knowledge spillover. The dummy variable proprietary was coded 1 if one or more of Compustar's proprietary technologies was required for a project and 0 otherwise. Projects that require Compustar's proprietary technologies generally make such technology the center of the project. The Compustar engineers coded the variable drawing upon their expertise and the records in the contract files.

Disrupt was a dummy variable that indicated whether a project had the potential to create reputational spillovers. Compustar managers indicated that the projects most important to their reputation were ones that could shut down significant portions of customers' "data centers." Data centers house mainframes, servers, and related devices and do the bulk of a firm's data processing and networking. Such an event is both costly for the customer who suffers it and highly visible, as it is likely to become a topic of discussion among chief informa-

\footnotetext{
${ }^{4}$ The actual range was $1-6$, as the engineers did not code any project as a 7 .
} 
tion officers. Discussion of this type is especially relevant for Compustar, given that its customers are primarily Fortune 500 corporations. Data center work is the heart of Compustar's area of expertise and forms the basis of its reputation for technical excellence, as it originated as a company manufacturing data center hardware. Compustar has been working in data centers since at least the 1970s. The company's engineers and managers agreed that data center incidents had the greatest potential to influence its reputation in the industry. The Compustar engineers coded the variable "disrupt" as 1 if a project had the potential to shut down a "significant portion" of a customer's data center, and 0 otherwise.

Although this study's hypotheses focus on spillovers, other factors could also influence the level of contract detail and/or the use of subcontractors. When the quality of output is difficult to measure, firms like IT suppliers will tend to use employees to perform work (Poppo \& Zenger, 1998). Firms will integrate to control (and measure) inputs because monitoring the output of another firm, such as a subcontractor, would be too costly (Barzel, 1982, 1989). The variable measurement was designed to capture the cost of evaluating quality ex post, solely on the basis of the technological nature of a project. Compustar stipulated that this variable be coded by its engineers as a dummy variable; 1 indicated that quality was difficult to determine, and 0 , that it was readily apparent. The question that determined the value of this variable was whether a brief, inexpensive test or inspection could determine the quality of the work done on a project.

Another alternative explanation for subcontracting is that firms will resort to this practice when they lack the requisite internal capabilities. A lack of internal capability may also raise the cost of writing highly detailed contracts because the firm is less familiar with the specifics of a given task. Compustar was weak relative to its competitors in programming and working on hardware manufactured by other vendors; the company had only begun offering stand-alone programming when it entered the IT services business, and many firms had this capability. Programming was a dummy variable coded 1 if a project primarily involved programming and 0 otherwise. Compustar also lacked distinctive expertise in working on hardware from other firms. Other hardware was coded 1 if a project involved working on hardware from another vendor and 0 otherwise. Compustar engineers coded both measures.

It may also be the case that strong internal capabilities influence subcontracting and contract detail. Compustar had superior (relative to competi- tors) internal capabilities in working on mainframes and hardware that the company had manufactured. These were not specific assets, as other vendors could also provide these services, but Compustar had employees with world-class capabilities in these areas. Compustar hardware was coded 1 if a project involved working on Compustar-manufactured hardware and 0 otherwise. Compustar engineers were acknowledged experts at servicing all mainframes, as they have been designing and manufacturing them since the 1970s and are Compustar's main product. Mainframe was coded 1 if a contract involved working on a mainframe computer and 0 otherwise. ${ }^{5}$

The coding process was as follows: Each engineer coded the same 80 randomly selected contracts. Then the two engineers and I went through all 80 cases to look for coding discrepancies. We found three for "disrupt," three for "measurement," two for "programming," and five for "reuse." After a brief discussion, the engineers clarified the conflicts and agreed that they were using the same criteria as they coded the remaining contracts.

Compustar managers suggested that contract detail and subcontracting activity might have varied over time as the IT services business developed and the firm increased staff to meet rising demand. Over time the amount of detail in the contracts steadily decreased as Compustar learned more about the IT services business and developed a reputation in this area. Subcontracting was thought to follow a slightly different trajectory; it was initially used extensively to meet a demand that was growing faster than internal capacity, but then began to level off later in the sample period as capacity caught up with demand and demand began to fall off slightly. Two time variables were included: Time trend, a linear variable coded 0 for 1986, 1 for 1987, and so on up to 12 for 1998, was included in all models. I also included time trend squared, a nonlinear variable, to check for the subcontracting pattern suggested by Compustar managers. Thus, time trend squared was used only in the subcontracting regressions, not in the contract detail regressions.

Another alternative explanation is temporal asset specificity created by interdependence between customer and supplier. Customer dependence captured bilateral task interdependence between Compustar and customer personnel. Customer dependence was coded 1 if a customer was directly

\footnotetext{
${ }^{5}$ Some projects (e.g., programming) do not involve working on Compustar hardware or hardware from other firms, so these categories are not mutually exclusive.
} 
involved in a project in such a way that Compustar had to depend upon the customer to complete its task(s). Such interdependencies are described in the contracts, so the two Compustar engineers coded these variables from the contracts.

It is also possible that contracting activity varies as a relationship develops between Compustar and its customer. As firms become embedded in social ties, they may change how they govern transactions (Larson, 1992; Uzzi, 1997). Detail may diminish if firms rely less on formal contracts and more on trust or social ties. To assess relationship development, I measured the extent of prior business between Compustar and each customer. Rather than merely counting the number of prior contracts, I weighted the contracts by their dollar value (lacking access to labor hours), as projects with higher dollar values should contribute more to relationship development than smaller projects. Prior relationship was the natural logarithm of the total dollar value of prior IT projects between Compustar and a customer. I used the logged value of prior dollars spent because I anticipated a nonlinear relationship. Going from nothing to $\$ 100 \mathrm{~K}$ is likely to have a greater effect on the development of a relationship than going from $\$ 900 \mathrm{~K}$ to $\$ 1 \mathrm{M}$. One issue was that the dollar value was missing for 93 projects. I dealt with this by using the average dollar value of all projects to fill in missing data. The results were virtually identical if I coded missing dollar values as 0 .

The size of a project could also influence subcontracting and the detail of task descriptions. Large projects may require Compustar to supplement its internal resources and may require more detailed contracts. Project size was the dollar value of each current project as recorded in the contract.

Capacity constraints could also affect subcontracting. Compustar indicated that their busiest months, when capacity was most constrained, were the ends of the first three fiscal quarters (March, June, and September), and November (because of shutdowns during the fourth quarter and a slowing of demand between Thanksgiving and Christmas). I found that 40 percent of the projects in my sample were from these four months. Peak months was a dummy variable coded 1 if a project originated during one of the four peak months and 0 otherwise. ${ }^{6}$

Table 1 contains descriptive statistics for all variables. Correlations are generally low to moderate,

\footnotetext{
${ }^{6}$ The results, shown in Table 2, were robust to alternative measures of capacity constraints, including estimates of actual workload.
}

and variance inflation factors for all variables are less than 2; thus multicollinearity was not a problem for this estimation. Simultaneity was also not a problem in this estimation because the independent variables were project characteristics that were known when a contract was negotiated and the subcontracting decision was made.

Because both dependent variables were categorical, I employed ordered probit estimation to examine contract detail and a standard probit model to examine subcontracting, using maximum-likelihood estimation as most appropriate for dealing with this type of qualitative data. The model estimated in this study was drawn from Maddala (1983).

I defined the population of projects as all projects that came to Compustar, and the sample was randomly drawn from this set. A customer's choice of whether to outsource an IT transaction should not affect the level of detail for projects that they do choose to outsource or the supplier's decision of whether to use a subcontractor.

\section{RESULTS}

I begin by examining influences on the level of detail that went into the Compustar-customer contracts in the sample. Model 1 of Table 2 included only the control variables. The model has a loglikelihood statistic of -556 . Project size $(p>.001)$ and the extent of the prior relationship $(p<.05)$ both led to more detailed task descriptions. The capability measures produced significant but opposing results. Projects involving other firms' hardware had more detailed contracts $(p<.05)$, but projects involving programming had less detailed contracts $(p<.01)$. Finally, task descriptions became less detailed over time $(p<.01)$. I return to the implications of these results in the Discussion section.

Model 2 of Table 2 adds the two spillover variables. The log-likelihood improves from -556 to -552 for this model, which is significant at the 99 percent level. Hypothesis $1 \mathrm{a}$ is supported, as projects with more reusable innovation were governed by more detailed contracts $(p<.01)$. Model 2 provides no support for Hypothesis 2a, as the potential to disrupt a customer's data center had no influence on task description.

Model 3 examines the supplier's decision to subcontract. Larger projects increased the likelihood of subcontracting $(p>.05)$. Subcontracting was more likely when a project involved hardware from other vendors $(p>.001)$ or programming $(p>.001)$. When it was difficult to measure quality, subcontracting was less likely $(p>.001)$. The use of sub- 


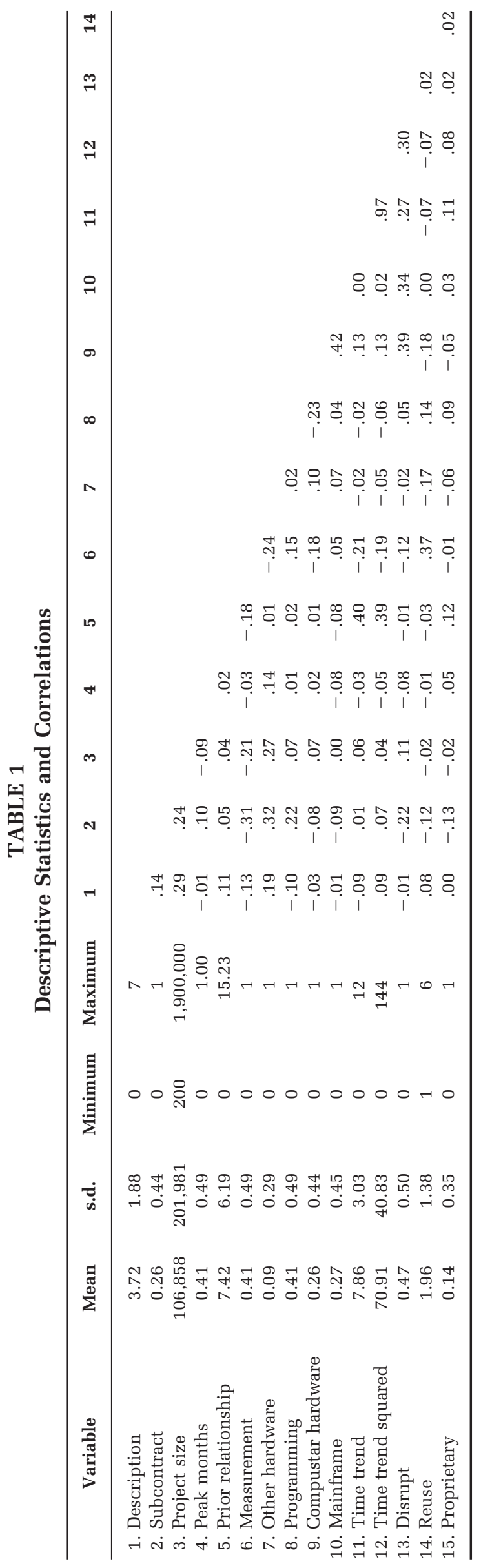


TABLE 2

Results of Regression Analyses

\begin{tabular}{|c|c|c|c|c|c|c|c|c|}
\hline \multirow[b]{2}{*}{$\begin{array}{l}\text { Independent } \\
\text { Variables }\end{array}$} & \multicolumn{2}{|c|}{$\begin{array}{l}\text { Model 1: Description, } \\
\text { Ordered Probit }\end{array}$} & \multicolumn{2}{|c|}{$\begin{array}{l}\text { Model 2: Description, } \\
\text { Ordered Probit }\end{array}$} & \multicolumn{2}{|c|}{$\begin{array}{c}\text { Model 3: Subcontract, } \\
\text { Probit }\end{array}$} & \multicolumn{2}{|c|}{$\begin{array}{c}\text { Model 4: Subcontract, } \\
\text { Probit }\end{array}$} \\
\hline & $\boldsymbol{b}$ & s.e. & $b$ & s.e. & $b$ & s.e. & $\boldsymbol{b}$ & s.e. \\
\hline Constant & $3.38 * * *$ & $(0.42)$ & $3.27 * * *$ & $(0.43)$ & $-3.42^{* * *}$ & $(0.86)$ & $-3.01 * * *$ & $(0.82)$ \\
\hline Peak months & & & & & 0.11 & $(0.19)$ & 0.10 & $(0.21)$ \\
\hline Measurement & -0.19 & $(0.13)$ & $-0.32^{* *}$ & $(0.14)$ & $-1.06^{* * *}$ & $(0.23)$ & $-1.21 * * *$ & $(0.25)$ \\
\hline Other hardware & $0.47^{*}$ & $(0.23)$ & $0.54^{* *}$ & $(0.23)$ & $1.05^{* * *}$ & $(0.32)$ & $0.91 * *$ & $(0.34)$ \\
\hline Programming & $-0.35^{* *}$ & $(0.13)$ & $-0.39 * *$ & $(0.13)$ & $0.69 * * *$ & $(0.20)$ & $0.86 * * *$ & $(0.22)$ \\
\hline $\begin{array}{l}\text { Compustar } \\
\text { hardware }\end{array}$ & $-0.30^{+}$ & $(0.16)$ & -0.27 & $(0.17)$ & $-0.43^{+}$ & $(0.25)$ & -0.35 & $(0.28)$ \\
\hline Mainframe & $0.13^{*}$ & $(0.15)$ & 0.11 & $(0.15)$ & -0.13 & $(0.24)$ & 0.19 & $(0.25)$ \\
\hline Proprietary & & & & & & & $-0.92^{* *}$ & $(0.30)$ \\
\hline Log-likelihood & \multicolumn{2}{|c|}{-556.01} & \multicolumn{2}{|c|}{-551.97} & \multicolumn{2}{|c|}{-121.99} & \multicolumn{2}{|c|}{-107.62} \\
\hline
\end{tabular}

$$
\begin{aligned}
& n=303 . \\
& { }^{+} p<.10 \\
& \quad * p<.05 \\
& { }^{*} * p<.01 \\
& * * * p<.001
\end{aligned}
$$

contractors initially increased and then leveled off over time. Capacity did not significantly affect subcontracting.

Model 4 adds the two spillover variables and results in improvement in the log-likelihood from -122 to -108 , which is significant at the 99 percent level. There are no significant changes to the control variables. Hypothesis $1 \mathrm{~b}$ finds mixed support, depending upon whether the knowledge spillovers related to existing knowledge or new knowledge that could be created during a project. A project's potential to generate new reusable knowledge had no effect on the use of subcontractors versus employees; however, projects that drew upon Compustar's existing proprietary technology reduced the probability of subcontracting $(p<.01)$. A project's potential to disrupt the customer's data center significantly lowered the likelihood of subcontracting $(p>.001)$, a finding that supports Hypothesis $2 \mathrm{~b} .^{7}$

7 The results for all models were robust to removing project size, which could be endogenous to the level of detail or subcontracting.

\section{DISCUSSION AND CONCLUSION}

In this study I integrated transaction cost theory and the knowledge-based view of the firm in order to better understand the governance of knowledge. These two theories have each had a significant impact on strategy because they speak to competitive advantage, but to date, they have primarily been applied to different topics that have not enabled taking advantage of their complementary potential. Transaction cost theory has a rich history that extends well beyond strategy into fields such as economics, sociology, and political science, but because of its focus on contracting problems and governance, the role of knowledge has not been fully incorporated. Some strategy researchers have argued that the contracting problems that have been the focus of transaction cost theory are really second-order effects and that knowledge or capability effects are actually much more important. Although the knowledge-based view has been very useful in highlighting the central role of knowledge creation and management in competitive advantage, the only governance issues it has addressed are those relevant to keeping knowledge within a firm. Transaction cost researchers need to better respond to Williamson's (1999) call to more effec- 
tively incorporate capabilities and knowledge into transaction cost theory, and scholars taking a knowledge-based perspective also need to consider different ways that governance may influence the creation and protection of knowledge.

Rather than viewing transaction cost theory and the knowledge-based view as incompatible, this study explored how they can inform one other by examining a topic that is central to both theorieshow the creation and protection of knowledge affect governance decisions. First, I found that positive knowledge spillovers resulting from potentially reusable knowledge influenced a supplier's management of the customer relationship (leading to more contract detail) but did not affect subcontracting decisions. On the other hand, the potential for negative knowledge spillovers from losing existing knowledge influenced supply chain decisions (that is, it led to a preference for employees over subcontractors), but had no effect on the customer contract. Note that the variable assessing potential loss of existing knowledge, "proprietary," is not included in models 1 and 2, but Table 1 shows that it is totally uncorrelated with contract detail. The variable is completely insignificant if it is included in the contract detail regressions (and does not affect the other results).

Different types of knowledge spillovers (from new knowledge or from existing knowledge) lead to different governance responses. When protecting existing knowledge, appropriability (leakage) is the key issue; the firm studied here, Compustar, avoided subcontracting. Creating new knowledge requires a clear definition of what to create; thus, aligned expectations and incentives were the key issues influencing the task descriptions in the customer-supplier contracts.

This finding that knowledge spillovers arising from new and existing knowledge are governed differently has interesting implications for the knowledge-based view and for transaction cost theory. Foss (1996) highlighted the fact that knowledge-based-view scholars such as Kogut and Zander (1992) have argued that knowledge and resources create a need for a shared code that necessitates the creation of a firm even in the absence of opportunism. What I explore by introducing elements of transaction cost theory is a knowledgebased view that incorporates opportunism. Subcontractors could be trained to use Compustar's proprietary technologies, so the risk of opportunism seemed to be the main reason to avoid subcontracting when Compustar's proprietary technology was required. I did not assume that all subcontractors were opportunistic-nor does transaction cost theory assume that all economic actors are oppor- tunistic. My assumption, drawn from transaction cost theory (see Williamson, 1985) is that some people (or subcontractors) are opportunistic, and firms must take this possibility into consideration because it is difficult to tell beforehand who will act opportunistically if the opportunity arises and who will not.

Alternatively, when new knowledge is at stake, the supplier studied here did not resort to integration, but rather, paid special attention to the customer contract by incorporating a high level of detail about the task. Opportunism still mattered, but it did not always result in integration. Scholars taking a knowledge-based view may wish to separate the governance of a firm's existing stock of knowledge from the governance of knowledge-creating activities, as transaction cost arguments about integrating to avoid opportunism may be more relevant to the former. The potential for opportunism still exists when a firm is creating new knowledge, but during knowledge creation the main concern seems to be making sure the right knowledge is created.

Transaction cost theorists, however, also need to consider how to incorporate knowledge. The differing impacts of creating new knowledge and protecting existing knowledge suggest that knowledge is more than a firm asset that needs to be protected. Transaction cost theory is fundamentally concerned with crafting governance mechanisms that protect a firm and its resources. This study suggests that a clear definition of roles and responsibilities in a contract can facilitate knowledge creation. A contract helps its parties realize the potential from their interaction. Once valuable knowledge has been created, integration becomes a more important aspect of governance, as protecting the knowledge becomes of greater importance. Social factors are also likely to be important (Granovetter, 1985), but they do not obviate the need for a clear contract with well-defined roles and responsibilities.

Some debate about the role of contracts in business exchange has centered on whether contracts complement (Poppo \& Zenger, 2002) or substitute for relational governance or trust (Gulati, 1995). Some researchers have argued that opportunism is not relevant once the parties to a contract get to know one another, so contracts should be phased out as a relationship develops (e.g., Ring \& Van de Ven, 1992). However, I found no elimination of contracts as relationships developed. The primary drive of detailed task descriptions may be complexity rather than trust, as the likelihood of conflicting expectations is higher for complex transactions. I actually found that more extensive prior relationships led to more detail, which may imply that in 
complex exchanges involving the creation of new knowledge spillovers, additional detail may actually help the parties develop a better relationship by creating the foundation for a common understanding. Firms seem to learn what task detail to include as they work together over time (Mayer \& Argyres, 2004). If my variable "prior relationship" is interpreted as a measure of embeddedness, this study's findings also imply that a firm does not abandon contracts even when it is increasingly embedded in a social relationship with another firm. More work is needed to understand how social embeddedness influences different aspects of a contract.

To fully unpack the implications for transaction cost theory, I discuss four possible mechanisms behind the finding that the potential for a project to create reusable knowledge did not influence Compustar's decision about use of employees versus subcontractors. First, the variable used in the analysis may not have been a good proxy for knowledge spillovers. This seems unlikely, however, as the variable was explicitly coded by experienced Compustar engineers to consider knowledge reuse, not just level of innovation. A second explanation is that Compustar's involvement in a project management capacity may have been sufficient to ensure that it would capture any knowledge generated during a project. Even when projects were subcontracted, a Compustar employee always served as the main point of contact with the customer. Third, capturing potentially reusable knowledge may be a second-order effect when compared to capability concerns and contractual hazards such as measurement costs when allocating employees to projects. Finally, it could be that Compustar only cared about being able to reuse certain types of knowledge. Thus, subcontracting would be fine for areas that were not being developed as core competencies. The Compustar engineers indicated that all but the first explanation were important in different situations in which reusability was an issue. This assessment highlights the fact that there are many mechanisms short of integration firms may employ to facilitate transactions while still protecting their interests. But protecting critical existing knowledge did require integration.

Like threats to Compustar's proprietary technology, potential disruption of a customer's data center resulted in a strong preference for employees. One alternative explanation for this result is that projects that could disrupt a customer's data center were given to employees for reasons unrelated to Compustar's reputation; perhaps Compustar avoided subcontractors in these cases because of strong internal capabilities. The significance of the variable "disrupt," despite the presence of two internal capability variables, indicates that this was not the case. Though other capabilities also existed at Compustar, the two capabilities represented in this analysis were both relevant to data center activities, which suggests that capabilities did not drive the significance of "disrupt." A second explanation that could affect subcontracting is capacity. Compustar might not have subcontracted activities that were central to its reputation because it had sufficient in-house capacity. Capacity certainly affects the overall level of subcontracting, but it should not affect the decision of which projects to subcontract. Capacity is less of an issue in this industry than in many others because IT engineers tend to be mobile employees with high turnover. Compustar is located in Silicon Valley, an area with many IT engineers, which limited the adjustment costs of modifying capacity. The variable "peak months," used to capture and empirically test for capacity constraints, was positive but not significant. Compustar might have been more likely to subcontract when capacity was tight, but this was not a significant effect, and it did not influence the main results of the study. Alternative efforts to represent capacity via estimates of actual workload led to identical results.

Although capacity did not play a significant role, capabilities played a somewhat surprising role in the detail of task descriptions. Projects that involved programming resulted in less-detailed task descriptions, while projects involving hardware from other manufacturers resulted in more detail. Compustar personnel indicated that programming projects were often intentionally left ambiguous to allow the customers to direct the Compustar resources to respond flexibly as priorities changed, a tactic that is in line with Crocker and Reynolds's (1993) findings in their study of Air Force procurement. There is little value in negotiations to describe a task when a brief section that gives the customer the right to make changes will suffice. Projects involving hardware from other manufacturers may have resulted in more-detailed task descriptions because Compustar needed more direction about what exactly was expected when dealing with less familiar equipment. A customer might also want more detail to ensure that the goal of a project was clear. Several interviewees mentioned misunderstandings over what exactly was to be done when Compustar was working on relatively unfamiliar equipment. Compustar always completed the task, but the misunderstandings affected cost and schedule.

One of the strengths of this study is its use of microanalytic data from a single firm. Such de- 
tailed, transaction-level data offer insights and detailed proxies for theoretical constructs that are not available from larger, interindustry studies. Because the data were collected from a single firm, however, the generalizability of the findings is limited. Although research in other settings is needed to test the applicability of the results, other studies of contracting practices complement this paper (see Shelanski \& Klein, 1995) and suggest that the results should generalize to many high-technology industries, such as aerospace, software, telecommunications, and semiconductors), where knowledge and reputation are critical. Other industries that emphasize project-based organization, such as machine shops, construction, and film and television production, may also learn from the way IT firms organize their projects. Issues such as the potential to devalue a firm's reputation from poor performance clearly exist outside the IT industry, as do challenges in managing knowledge-related spillovers.

Future research can also unpack the potential moderating role of social embeddedness, trust, and repeated interaction to determine how these variables affect decisions to subcontract and to include detailed task descriptions in contracts. Developing trusting relationships with subcontractors may make firms more willing to subcontract when their reputations are at stake.

Another direction for future research is exploring the strategic significance of different aspects of contracts (e.g., contingency planning, enforcement provisions, dispute resolution mechanisms) to shed light on how firms can write more effective contracts. The debate about contracts and trust has primarily focused on contracts in their entirety. It might be the case that some aspects of a contract, such as penalty clauses, will be eliminated as the parties develop a relationship, while other aspects, such as contingency planning, are required regardless of how well the parties know one another.

This integration of transaction cost theory and the knowledge-based view of the firm has important implications for managers. The level of task description in a contract and a firm's choice of employees versus subcontractors are both important, but they are important primarily for different types of transactions. Managers need to understand how to make effective governance decisions when a current project has the potential to affect future projects. Sustainable competitive advantage requires a continual focus on how current activities influence a firm's future position. Effectively managing projects that may generate spillovers can play an important role in helping a firm build (by incorporating reusable knowledge) and maintain (through preventing reputational damage or the loss of existing technology) a strong competitive position.

\section{REFERENCES}

Ahuja, G. 2000. The duality of collaboration: Inducements and opportunities in the formation of interfirm linkages. Strategic Management Journal, 21: 317-343.

Argyres, N. 1996. Evidence on the role of firm capabilities in vertical integration decisions. Strategic Management Journal, 17: 129-150.

Argyres, N., \& Liebeskind, J. 1999. Contractual commitments, bargaining power, and governance inseparability: Incorporating history into transaction cost theory. Academy of Management Review, 24: 4963.

Azoulay, P. 2003. Acquiring knowledge within and across firm boundaries: Evidence from clinical trials. National Bureau of Economic Research, Cambridge, MA.

Barzel, Y. 1982. Measurement cost and the organization of markets. Journal of Law and Economics, 25: 2748.

Barzel, Y. 1989. An economic analysis of property rights. Cambridge, U.K.: Cambridge University Press.

Boerner, C. S., Macher, J. T., \& Teece, D. J. 2001. A review and assessment of organizational learning in economic theories. In M. Dierkes, A. Berthoin Antal, J. Child, \& I. Nonaka (Eds.), Handbook of organizational learning and knowledge: 89-117. New York: Oxford University Press.

Bresnahan, T. 1986. Measuring the spillovers from technical advance: Mainframe computers in financial services. American Economic Review, 76: 742-755.

Brickley, J. A., \& Dark, F. H. 1987. The choice of organizational form: The case of franchising. Journal of Financial Economics, 18: 401-420.

Chatman, J. A. 1991. Matching people and organizations: Selection and socialization in public accounting firms. Administrative Science Quarterly, 36: 459484.

Crocker, K., \& Reynolds, K.. 1993. The efficiency of incomplete contracts: An empirical analysis of air force engine procurement. RAND Journal of Economics, 24: 126-146.

Demsetz, H. 1991. The theory of the firm revisited. In O. Williamson \& S. Winter (Eds.), The nature of the firm: 159-178. New York: Oxford University Press.

Dollinger, M. J., Golden, P. A., \& Saxton, T. 1997. The effect of reputation on the decision to joint venture. Strategic Management Journal, 18: 147-140.

Eccles, R. G. 1981. The quasi-firm in the construction 
industry. Journal of Economic Behavior and Organization, 2: 335-358.

Erdem, T., \& Swait, J. 1998. Brand equity as a signaling phenomenon. Journal of Consumer Psychnology, 7: 131-157.

Fombrun, C., \& Shanley, M. 1990. What's in a name? Reputation building and corporate strategy. Academy of Management Journal, 33: 233-258.

Foss, N. 1996. Knowledge-based approaches to the theory of the firm: Some critical comments. Organization Science, 7: 470-476.

Granovetter, M. 1985. Economic action and social structure: The problem of embeddedness. American Journal of Sociology, 91: 481-510.

Grant, R. 1991. The resource-based theory of competitive advantage: Implications for strategy formulation. California Management Review, 33(3): 114-135.

Grant, R. 1996. Prospering in dynamically competitive environments: Organizational capability as knowledge integration. Organization Science, 7: 375-387.

Grossman, S., \& Hart, O. 1986. The costs and benefits of ownership: A theory of vertical and lateral ownership. Journal of Political Economy, 94: 691-719.

Gulati, R. 1995. Does familiarity breed trust? The implications of repeated ties for contractual choice in alliances. Academy of Management Journal, 38: 85-112.

Gulati, R., \& Singh, H. 1998. The architecture of cooperation: Managing coordination costs and appropriation concerns in strategic alliances. Administrative Science Quarterly, 43: 781-814.

Hall, R. 1992. The strategic analysis of intangible resources. Strategic Management Journal, 13: 135144.

Hart, O., \& Moore, J. 1990. Property rights and the theory of the firm. Journal of Political Economy, 98: 11191158 .

Hennert, J.-F. 1988. The transaction cost theory of joint ventures: An empirical study of Japanese subsidiaries in the United States. Management Science, 37: 483-497.

Houston, M. B. 2003. Alliance partner reputation as a signal to the market: Evidence from bank loan alliances. Corporate Reputation Review, 5: 330-342.

Itami, H. 1997. Mobilizing invisible assets. Cambridge, MA: Harvard University Press.

Jaffe, A. B. 1986. Technological opportunity and spillovers in R\&D: Evidence from firms' patents, profits, and market value. American Economic Review, 76: 984-1001.

Kim, S. T., Lin, J.-C., \& Slovin, M. B. 1997. Market structure, informed trading, and analysts' recommendations. Journal of Financial and Quantitative Analysis, 32: 507-524.
Klein, B., \& Leffler, K. B. 1981. The role of market forces in assuring contractual performance. Journal of Political Economy, 89: 615-641.

Kogut, B. 1988. Joint ventures: Theoretical and empirical perspectives. Strategic Management Journal, 9: 319-332.

Kogut, B., \& Zander, U. 1992. Knowledge of the firm, combinative capabilities, and the replication of technology. Organization Science, 7: 502-518.

Kreps, D. M. 1990. Corporate culture and economic theory. In J. E. Alt \& K. A. Shepsle (Eds.), Perspectives on positive political economy: 90-143. Cambridge, U.K.: Cambridge University Press.

Larson, A. 1992. Network dyads in entrepreneurial settings: A study of the governance of exchange processes. Administrative Science Quarterly, 37: 76104.

Liebeskind, J. 1997. Keeping organizational secrets: Protective institutional mechanisms and their costs. Industrial and Corporate Change, 6: 623-663.

Macaulay, S. 1963. Non-contractual relations in business. American Sociological Review, 28: 55-70.

Maddala, G. S. 1983. Limited dependent and qualitative variables in econometrics. New York: Cambridge University Press.

Madhok, A., \& Tallman, S. B. 1998. Resources, transactions and rent: Managing value through interfirm collaborative relationships. Organization Science, 9: $326-339$.

Mansfield, E. 1988. The speed and cost of industrial innovation in Japan and the United States. Management Science, 34: 1157-1168.

Mansfield, E. 1991. Academic research and industrial innovation. Research Policy, 20: 1-12.

Masten, S. E. 1988. A legal basis for the firm. Journal of Law, Economics, and Organization, 4: 181-198.

Mayer, K. J., \& Argyres, N. 2004. Learning to contract: Evidence from the personal computer industry. Organization Science, 15: 394-410.

Mayer, K. J., Nickerson, J. A., \& Owan, H. 2004. Are supply and plant inspections complements or substitutes? A strategic and operational assessment of inspection practices in biotechnology. Management Science, 50: 1064-1081.

Nickerson, J. A., \& Silverman, B. S. 2003. Why aren’t all truck drivers owner-operators? Asset ownership and the employment relation in interstate for-hire trucking. Journal of Economics and Management Strategy, 12: 91-118.

Pfeffer, J., \& Salancik, G. 1978. The external control of organizations: A resource dependence perspective. New York: Harper \& Row.

Pisano, G. P. 1990. The R\&D boundaries of the firm: An empirical analysis. Administrative Science Quarterly, 35: 153-176. 
Poppo, L., \& Zenger, T. 1998. Testing alternative theories of the firm: Transaction cost, knowledge-based, and measurement explanations for make-or-buy decisions in information services. Strategic Management Journal, 19: 853-877.

Poppo, L., \& Zenger, T. 2002. Do formal contracts and relational governance function as substitutes or complements? Strategic Management Journal, 23: 707726.

Rao, A. R., \& Ruekert, R. W. 1994. Brand alliances as signals of product quality. Sloan Management Review, 36(fall): 87-97.

Rindova, V. P., \& C. J. Fombrun. 1999. Constructing competitive advantage: The role of firm-constituent interactions. Strategic Management Journal, 20: 691.

Ring, P. S., \& Van de Ven, A. H. 1992. Structuring cooperative relationships between organizations. Strategic Management Journal, 13: 483-498.

Shapiro, C. 1985. Consumer information, product quality, and seller reputation. Bell Journal of Economics, 13: 20-35.

Shelanski, H. A., \& Klein, P. G. 1995. Empirical research in transaction cost economics: A review and assessment. Journal of Law, Economics and Organization, 11: 335-361.

Stuart, T. E. 1998. Network positions and propensity to collaborate: An investigation of strategic alliance formation in a high technology industry. Administrative Science Quarterly, 43: 668-698.

Teece, D. J. 1986. Profiting from technological innova- tion: Implications for integration, collaboration, licensing, and public policy. Research Policy, 15: 285-305.

Tsui, A. 1984. A role set analysis of managerial reputation. Organizational Behavior and Human Performance, 34: 64-96.

Uzzi, B. 1997. Social structure and competition in interfirm networks: The paradox of embeddedness. Administrative Science Quarterly, 42: 35-67.

Williamson, O. E. 1985. The economic institutions of capitalism. New York: Free Press.

Williamson, O. E. 1996. Mechanisms of governance. New York: Oxford University Press.

Zollo, M., Reuer, J., \& Singh, H. 2002. Interorganizational routines and performance in strategic alliances. Organization Science, 13: 701-713.

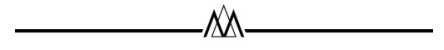

Kyle J. Mayer (kmayer@marshall.usc.edu) is an assistant professor of strategic management for the Marshall School of Business at the University of Southern California. He received his Ph.D. in business administration from the Haas School of Business, University of California, Berkeley. His research, drawing largely on transaction cost, resource-based, and learning perspectives, examines interorganizational relationships, contracts, and vertical integration.

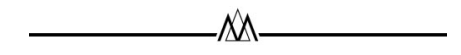

